\title{
Editorials
}

\section{INDETERMINATE LEPROSY}

"Indeterminate Leprosy" is a subject of some confusion. The term dates back to the Havana Congress (1948) at which indeterminate was designated as a rather indistinct clinical group, with macules or nerve involvement, of variable resistance and uncertain evolution. The histology showed simple inflammation and bacilli, if present, were few. The only other groups were tuberculoid and lepromatous. The Madrid Congress (1953) introduced the borderline group, but did not modify significantly the definition of indeterminate. No mention was made of its histology.

The usage of the term indeterminate has been somewhat confused in practice by the fact that the official classification of leprosy is primarily clinical and the wish of many Indian workers to designate maculo-anaesthetic as a separate group. Thus Fernandez (1953) thought that for reasons of practical convenience all macular patients should be classified as indeterminate, while Dharmendra in stressing the differentiation of indeterminate and maculo-anaesthetic admitted that the distinction could be difficult.

Despite some confusion there is no doubt that "indeterminate" has usually been applied to early lesions, early that is in terms of evolution if not in years, which are sometimes self healing, and that as the name implies they are called indeterminate because they have not yet reached the stage when they can be called anything else. Browne (1966) uses the term in this sense, of a case that cannot be "determined", and so do Ridley and Jopling (1966). One wonders if that is what was intended by the Congresses of Havana and Madrid. The primarily clinical definition and the presumed intention that the term was to be applied to immature and otherwise unclassifiable lesions are probably consistent with each other if classification is based exclusively on clinical evidence. But other sources of evidence are being utilized on an increasingly wide scale, and under these circumstances the two meanings of the term are not necessarily consistent, though usually they are. In this, as in other aspects of classification, there is a possible conflict of interest between workers in rural areas and others. If there are occasions when it is still useful to have a group to which macular patients can be assigned without resort to other considerations it is difficult to see why it could not be labelled macular anaesthetic or macular non-anaesthetic (with appropriate clinical definitions). To those who accept that the spectrum of leprosy is essentially a matter of immunology, surely almost everybody, and wish to classify it accordingly, there is need for a more flexible group to which to assign patients who, on all the evidence available, are still unclassifiable within the spectrum. It would seem a pity if this group, or more correctly non-group, could not be called by the time honoured "indeterminate" which so aptly describes it.

Used in this sense (as it will be throughout the remainder of this paper), 
indeterminate is a relative term. On the Havana classification, with a two group spectrum, almost every patient with post-primary lesions would be readily identifiable as tuberculoid or lepromatous. If one uses a spectrum with five groups, or possibly even more, one might be unable to assign the patient exactly to any of the groups and to this extent he would be indeterminate, though one could still say that he was broadly tuberculoid or lepromatous. A patient might be classifiable as BT clinically though histologically indeterminate. In this case if the clinical findings were definite the classification would be BT. A case that was histologically indeterminate after the examination of two sections might become determinate after the examination of serial sections, or following a second biopsy.

The histology of indeterminate leprosy is that of a relatively simple non-specific inflammation and the criteria by which it is defined are those by which early leprosy is diagnosed. This involves mainly the demonstration of nerve involvement, or the detection of acid-fast bacilli in nerve or certain other situations such as the sub-epidermal zone or arrectores pilorum muscles. The histology has been described in greatest detail by Bungeler (1943). Recent papers which discuss the current problem of diagnosis are those of Binford (1971) and Nayer, Narayanan and Job (1972).

Histologically, leprosy ceases to be indeterminate and becomes classifiable with reasonable accuracy when a granuloma develops. This may be of the epithelioid cell type, usually first seen in nerves or sub-epidermal zone, or it may be a macrophage granuloma, loaded with bacilli, which usually makes its first appearance in a peri-neural or peri-vascular situation (Ridley, 1973). The problem of early classification, therefore, is to find a granuloma which, being very small, often requires the examination of serial sections. Unless a very careful search is made it is quite likely that early leprosy will become determinate to the clinician sooner than the histologist (Myrvang et al., 1973). On the other hand once the granuloma has developed the histology will usually give a more accurate and up-to-date indication of classification than the clinical picture since the latter is slower to change when there is an immunological shift.

With regression following successful prolonged therapy the granulomata eventually resolve and the histology reverts to indeterminate. Clinically it is likely that the stigmata will remain until healing is complete and the indeterminate picture will not recur.

In short, indeterminate should be regarded as a necessary term of convenience. The characteristics of indeterminate patients are fairly homogenous and can be described, but as a group indeterminate can only be defined in negative terms.

\section{References}

Binford, C.H. (1971). The histologic recognition of the early lesions of leprosy. Int. J. Lepr. $39,225$.

Browne, S.G. (1966). Observations on the macular series in African leprosy. Int. J. Lepr. 34, 175.

Büngeler, W. (1943). Die pathologische Anatomie der Lepra, II. Arch. f. Path. Anat. 310, 493. Dharmendra, (1963). The maculo-anaesthetic form of leprosy. Int. J. Lepr. 31, 161.

Fernandez, J.M.M. (1953). The pan-American classification of the forms of leprosy. Int. J. Lepr. $21,133$.

Havana Congress (1948). Fifth International Leprosy Congress: Technical resolutions of the congress. Int. J. Lepr. 16, 201.

Madrid Congress (1953). Sixth International Congress of Leprosy. Technicai resolutions. Int. J. Lepr. 21, 504. 
Myrvang, B., Godal, T., Feek, C.M., Ridley, D.S. and Samuel, D.R. (1973). Immune responses to Mycobacterium leprae in indeterminate leprosy patients. Acta Path. Microbiol. Scand. Sect. B. 81, 615 .

Nayar, A., Narayanan, J.S. and Job, C.K. (1972). Histopathological study of early skin lesions in leprosy. Arch. Path. 94, 199.

Ridley, D.S. (1973). The pathogenesis of the early skin lesion in leprosy. J. Path. 111, 191.

Ridley, D.S. and Jopling, W.H. (1966). Classification of leprosy according to immunity. Int. J. Leepr. 34, 255.

D.S. Ridley

\section{THE NOSE IN LEPROSY: STEPS TO A BETTER UNDERSTANDING}

The face we present to the world matters a great deal to most people. Its most prominent feature, the nose, is a focal point of emotional feelings, whether of family pride or of private resentment at one's genetic inheritance. Because personal attractiveness is at stake, diseases which may disfigure the nose are inevitably charged with high emotional content, and none more so than leprosy. The cosmetic problems which confront the sufferer from lepromatous leprosy are severe enough. Unfortunately the nasal deformity which he dreads is distinctive, a stigma which he cannot conceal, and which betrays to the world the disease from which he is suffering. To the patient, the involvement of his nose is a profound cause of anxiety, and one which merits far more attention than it has often received in the past.

The early leprologists were in no doubt as to the importance of the nose in leprosy, though their concern was not so much with the psychology of the patient as with the acid-fast bacilli they discovered in his nose. Here, their observations were of great relevance and importance. The universality of nasal involvement in what we now call lepromatous leprosy was widely recognised. Several leprologists observed that the nasal mucosa could be infected very early in the disease. Leloir (1886), Goldschmidt (1891), Glück (1897) and Jeanselme and Laurens (1897) all made this observation. Nasal involvement was associated with a nasal discharge in which acid-fast bacilli could be found, of ten in large numbers. Jeanselme (1934a) expresses this succinctly as follows. "Le muco-pus ... contient souvent d'innombrables bacilles agglutinés en boules epineuses. Ce sign assure donc le diagnostic dès les premiere phases de l'évolution morbide".

The severity of nasal involvement as compared with skin and internal organs was also recognised. Cohn (1890), Glück, and Breda, are all quoted by Klingmuller (1930). Schäffer (1898) demonstrated that large numbers of acid-fast bacilli could be projected in coughing, sneezing, and in normal speech, in one patient 185,000 bacilli to a distance of $1.5 \mathrm{~m}$ in $10 \mathrm{~min}$. There was of course no proof that the bacilli concerned were in fact Myco. leprae, neither was it possible to check their viability. Questions about this were nevertheless raised by Jeanselme (1934b).

When some workers, notably Goldschmidt (1891), Sticker (1897) and Schäffer (1898), proceeded to propose the nasal mucosa as the site of primary infection in leprosy, they ran into difficulties. Up till this point, the study of leprosy had largely been confined to western Europe, and among patients in whom the lepromatous form predominated. With the development of research in the Philippines, India, and Africa, the non-lepromatous forms of the disease came into 
prominence, and tuberculoid, and later, indeterminate leprosy were recognised. Among these, the concept of a primary involvement of the nasal mucosa could not be sustantiated, and for this and other reasons interest in the nose declined, with serious detriment both to patients and to the progress of knowledge. Nevertheless, Rogers and Muir (1946) stated, "In some cases, where there are no external signs of disease visible, bacilli may be found in the nasal discharge. Such patients are a special danger to the community, as they may spread the disease without knowing that they are suffering from it." Prabhu (1946) also drew attention to the early involvement of the nasal mucosa in lepromatous leprosy.

In 1964, Cochrane stated, "The early changes in the nose have never been thoroughly investigated". It is instructive to consider some of the reasons for the neglect of the nose in leprology during the past 40 years.

First is undoubtedly the low priority given to the examination of the nose at many centres. The earlier leprologists, concerned mainly with relatively few patients in a sophisticated European setting, were able to undertake an exhaustive examination with the help of appropriate consultants. A generation later, the centre of concern in leprosy had shifted to the developing countries, where a comparatively small body of leprologists found themselves confronted with large numbers of patients, major administrative problems, and the need to organise leprosy control activities, all too often in conditions of professional isolation. Only in exceptional circumstances was a specialist ophthalmologist or otorhinologist likely to be within reach of the centres where the relevant leprosy patients could be found in significant numbers. In such circumstances, as the writer knows only too well, priority had to be given to the most pressing issues, and as, at any rate in the pre-sulphone days, little could be done to help the patient where his nose and eyes were concerned, these aspects of leprology suffered from neglect. At most centres in Africa and India, rhinoscopy was not undertaken as routine, reliance on the situation in the nose being placed chiefly on the results of nasal smears and the subjective statements of patients.

Unless undertaken as routine, anterior rhinoscopy can lend itself to misleading conclusions. In the normal nose, the inferior turbinate, protruding into the lumen, easily catches the eye, and in very early lepromatous leprosy pathological swelling, discolouration and a granular or nodular appearance of this structure rivets attention. As the disease progresses, though still may be at an early stage, the inferior turbinate shrinks, and may be eroded and almost disappear from view, but by this time the septum is certain to be involved, and may be ulcerated. This dramatic appearance instantly catches the eye of the examiner, and it is easy to conclude that it is the septum which is the focal point of the infection. The theory of a primary infection of the nasal septum, induced by trauma, is thus readily understood.

A second source or error is the fallacy, engendered by the results of nasal smears, that leprosy in the nose simply reflects the general situation elsewhere in the body, with the disease in the nose having no distinctive features, and advancing parallel with the advance of the disease in the body as a whole. Thus Cochrane (1947) reporting on patients at Chingleput, found positive nasal smears in $36.59 \%$ of L1 (early) cases, $85.88 \%$ of L 2 (established) cases, and $100 \%$ of L3 (late) cases of lepromatous leprosy. Inevitably with such findings the belief gained credence that nasal smears are of only secondary importance, in that the information gained could have been gathered more easily, and with less discomfort to the patient, from routine skin smears. 
Cochrane's findings were based on nasal smears. While Muir (1938) mentions the inferior turbinate as a suitable site for smearing, all other authorities advise the nasal septum, and the anterior segment of it, as is made clear, with one exception, by the choice of instruments advocated, vide Cochrane (1964), Wade (1935), Goodwin (1967) and Dharmendra (1967) who mentions a point $1 / 2$ in from the orifice as suitable. The one exception is Browne (1965) whose suggestion of a sharpened piece of bicycle spoke, does provide access to deeper levels. Davey and Barton (1973) in a study of 100 patients, have shown that of all areas readily available to the examiner, the anterior segment of the septum is the one least likely to provide a reliable sample of the bacteriological situation in the nose, especially in early cases. Smears from this area in such cases frequently will not yield results significantly different from those found in the skin, whereas had the inferior turbinate been utilised, or the septum itself been examined at a deeper level, very different results would frequently have been obtained. Even with the use of routine anterior septal smears Davey (1959a,b) and Browne (1965) did observe that under chemotherapy the clearance of acid-fast material from the nose sometimes took longer than from the skin, and in relapse the nose could yield positive findings at an early stage. Some unusual features regarding leprosy in the nose could have been suspected from these findings.

The technique of nasal smearing yields material scraped from not more than 1 $\mathrm{cm}^{2}$ of the nasal mucosa, out of a total area of $70 \mathrm{~cm}^{2}$ and over liable to involvement in leprosy. The earlier procedure of wiping the interior of the nasal cavity with a pledget of cotton wool was a procedure better calculated to reveal Myco. leprae in their true numbers, but in general the far simpler procedure of examining the nasal discharge, which is drawn from this entire affected area, is greatly to be preferred. This procedure, utilised by the early leprologists, suffered decades of neglect, and Pedley deserves the gratitude of leprologists and patients alike, for resurrecting it. Davey and Rees, in this issue of the Leprosy Review, both demonstrate the frequency of highly bacilliferous nasal discharges in very early lepromatous leprosy, and give quantitative values for the numbers of bacilli involved. The only situations in which a nasal smear could have advantage over a specimen of nasal discharge are (a) in the very temporary phase when a very early nasal infection has not yet reached the stage of producing an inflammatory exudate, a situation only arising as the lepromatous type of the disease is just developing, (b) in a patient whose nasal discharge has dried up as a result of chemotherapy and (c) in the late stages when with gross secondary infection, especially in atrophic rhinitis, a satisfactory specimen of the discharge may be difficult to obtain.

A third reason for delegating the examination of the nose to a secondary position was the fear, applicable to all techniques, that preparations could be contaminated with saprophytic acid-fast organisms, and spurious positive findings result. A serious misconception arises here. The specific nasal discharge in leprosy is not a mucoid discharge in which Myco. leprae may be floating. It is an inflammatory exudate derived from an intensely lepromatous granuloma within the nasal mucosa, the exudate from which is of high cell content, consisting of macrophages, usually in very large numbers, easily identified under the microscope, and containing intra-cellular acid-fast bacilli, usually displaying globus formation in all its stages. This is a finding specific for leprosy, and doubt could only arise in the very earliest stages, when individual bacilli, escaping from the involved epithelium of mucous glands could be found in a specimen on their 
own. In several hundreds of examinations the writer has never witnessed this appearance without at the same time encountering at least one focus of macrophages in the specimen where the ingestion of acid-fast bacilli was evident. In practice therefore, saprophytic acid-fast bacilli pose no significant problem. Bacteriological examination of the nose may be highly revealing, and is indicated in every case of suspected lepromatous leprosy.

A fourth problem arises from the frequent reticence of patients to tell the truth regarding their noses. In the writer's experience in India, at any rate, the psychological trauma resulting from nasal infection was so profound that at a first consultation patients with obvious nasal problems said nothing about them, and when questioned, would admit to symptoms, but be vague as to their date of onset. It was only later, when hope was beginning to replace despair, as a result of chemotherapy and care of the nose, that patients felt able to tell the full story of their sickness, and it was quite remarkable how frequently nasal symptoms figured among the earliest signs of it, with no leading questions being asked.

More recently, the widespread availability of dapsone has led to further confusion. Because they have come for treatment, patients attending at hospitals and clinics will rarely admit that they have already taken some dapsone tablets on their own. Many a patient, presenting with what looks like active lepromatous leprosy, with skin smears highly positive, and a M.I. of up to 5 or even 10 , may be unable to offer a specimen of nasal discharge, or if he can, a discharge no more bacilliferous than skin, when in fact he has taken some dapsone tablets for a few weeks. Because the nasal infection responds so quickly to dapsone, this period may have been quite sufficient for bacteriological improvement in the nose to have masked its significance.

The nose in lepromatous leprosy thus presents many traps for the unwary.

A resurgence of interest in the nose in leprosy during the last three years owed its origin to the application by Shepard (1961) of quantitative and cultivation techniques to nasal qashings from patients with lepromatous leprosy. The studies of Goodwin (1967), Pedley (1970,1973a, b), Davey and Rees (1973,1974), Davey and Barton (1973), Barton et al., (1973), Barton (1974), McDougall et al., (1974) in the human subject, and of McDougall, Rees and Weddell (1973) and Rees, McDougall and Weddell (1974) in the mouse, and Kirchheimer (1973) in the armadillo, all point to a single conclusion. In lepromatous leprosy, in man, in the immunologically suppressed mouse, and in the armadillo, the nasal mucosa is a site of election for Myco. leprae of particular interest and significance.

Progress in this aspect of leprology has occurred solely because leprologist, bacteriologist, otorhinologist and pathologist have together brought their distinctive experience and skills to bear on a problem of common interest and concern. This issue of the Journal includes the studies of McDougall, Rees and Weddell on the mouse, the clinical and bacteriological study of Davey and Rees. and a clinical study by Barton, from the standpoint of an otorhinologist.

The predilection of Myco. leprae for the nasal mucosa has important consequences.

(a) It is inconceivable that the discharge of millions of viable Myco. leprae from the nose daily has no relation to the transmission of leprosy. The enormous numbers involved are now well documented. Rees (Davey and Rees, 1973) demonstrated the presence of viable Myco. leprae in 100\% of 31 specimens examined by the mouse footpad technique. Holmes and Hilson (1973) offered convincing evidence that the morphological index is an underestimate rather than an overestimate of the proportion of viable Myco. leprae in a laboratory 
preparation, and a figure of $3.1 \times 10^{7}$ viable bacilli for fourteen $24 \mathrm{~h}$ specimens and $1.9 \times 10^{7}$ viable bacilli for 17 single specimens of nasal discharge $30 \mathrm{~h}$ and more after production of the specimen, by Rees on the basis of the M.I. is valid. As Browne (1973) put it, "It is the abundant mucoid discharge from the hyperaemic nasal mucosa that is probably the vehicle for the exit of the vast majority of Myco.leprae leaving the body of the infected host."

(b) The persistence of viable bacilli in nasal discharge kept in the dark, and dessicated in the atmosphere, has also been demonstrated by Rees, in 3 specimens up to 2 days, and in 1 specimen up to 7 days (Rees and Davey, 1973). While sunlight may be expected rapidly to destroy bacilli discharged onto the open ground, dust and fomites in dark houses and insanitary conditions may obviously harbour living bacilli long enough for these to be a source of infection to others. A rational explanation can now be offered for the frequent infections in leprosy which arise outside the circle of close and intimate physical contact.

(c) The very early and serious involvement of the anterior part of the inferior turbinate must once again arouse suspicion as to whether in persons lacking resistance to Myco. leprae, inhalation is a possible means of infection. Projecting into the main stream of inhaled air, moist, and constantly cooled by the air passing over it, the anterior end of the inferior turbinate is the first structure in the nose likely to be encountered by inhaled microscopical material, and obviously provides conditions congenial to Myco. leprae. Now that we know that the bacillus can survive for some days in dust, what was thought to be a closed subject is once again wide open. Findings among children of patients at Culion long ago do not negate the possibility of infection by inhalation, if the constant association between nasal involvement and the gross immunological defect found in lepromatous leprosy is appreciated. While no child was found to show a primary nasal infection (i.e. a positive anterior septal smear), 13 out of 24 children with primary skin lesions did produce positive nasal smears. Nolasco and Lara (1949), reporting on the histological findings in "primary" lesions in 14 such children in Culion, found clear signs of an immunological response in 11, leaving 3 only as potential future lepromatous cases, a proportion far less than the proportion of children with positive nasal findings in the earlier series. If lack of the capacity for immunological response is the key to intranasal infection, the Culion findings certainly do not invalidate the possibility of a primary lesion on the inferior turbinate in such circumstances.

(d) Whether future study will negative or confirm the existence of infection in leprosy by inhalation, the very early appearance and special character of the infection in the nose could well have a sinister relationship to the development and spread of the disease. The frequent findings of a higher B.I. and M.I. in the nose as compared with skin must have meaning. The heavy involvement of the endothelium of blood vessels in the nose noted by Harman (Pedley, 1973a) and McDougall (Barton et al., 1973), means that the nose is an important contributor to the continuous bacillaemia which is characteristic of untreated lepromatous leprosy, and described in detail by Drutz, Chen and Wen-Hsiang (1972). Could the nose play a significant role in the degeneration of the borderline to the lepromatous type of disease? Evidence exists that it could. Dharmendra and Sen (1946) report on a patient with borderline leprosy with negative skin smears who nevertheless had a gross lesion in the nose loaded with Myco leprae. The 6 patients mentioned by Davey and Rees in this number of the Leprosy Review may also be significant.

We conclude where we began, with the patient. Quite clearly the internal 
examination of the nose needs to become a routine part of the clinical assessment of every patient with leprosy, certainly where the presenting type of the disease is of low resistance. Every worker in leprosy should be competent to undertake at any rate a simple anterior rhinoscopy, and carry it out as a habit. Simple procedures for the care of the nose such as indicated by Barton (1973) need to be as much a routine at leprosy hospitals and clinics as the dressing of ulcers, not only on medical grounds, but as a morale builder of great significance in a disease where psychological factors are of such importance. Finally, the rapid drying up of the nasal discharge after only a few weeks of chemotherapy, and the consequent obliteration of an important, and maybe the principal factor in the transmission of leprosy, gives a new urgency in leprosy control to the widest possible application of dapsone treatment.

One intriguing question remains to be asked. Can there be any relation between the ease and frequency with which patients are able to clear their nose in moist atmospheric conditions, and the well known higher prevalence of leprosy in damp as distinct from arid areas of the world?

\section{References}

Barton, R.P.E. (1973). Lepr. Rev. 44, 186.

Barton, R.P.E., Davey, T.R., McDougall, A.C., Rees, R.J.W. and Weddell, A.G.M. (1973). A bstracts of Tenth International Leprosy Congress, Bergen, p. 30.

Barton, R.P.E. (1974). Lepr. Rev. 45, (2), 135.

Browne, S.G. (1965): Int. J. Lepr. 34, 23.

Browne, S.G. (1973). Lepr. Rev. 44, 47.

Cochrane, R.G. (1947). A Practical Textbook of Leprosy. London: Oxford University Press, p. 104.

Cochrane, R.G. (1964). Leprosy in Theory and Practice, (Cochrane, R.G. and Davey, T.F., Eds). p. 613.

Davey, T.F. (1959a). Lepr. Rev. 30, 66.

Davey, T.F. (1959b). Lepr. Rev. 30, 141.

Davey, T.F. and Barton, R.P.E. (1973). Leprosy in India XLV, 54.

Davey, T.F. and Rees, R.J.W. (1973). Abstracts of Tenth International Leprosy Congress, Bergen, p. 46.

Davey, T.F. and Rees, R.J.W. (1974). Lepr Rev. 45, (2), 121.

Dharmendra, (1967). Notes on Leprosy, p. 312.

Dharmendra and Sen, N.R. (1946). Leprosy in India XVIII, 88.

Drutz, O.J., Chen, T.S.N. and Wen-Hsiang (1972). New Eng. J. Med. 287, 159.

Glück, L. (1897). First National Leprosy Congress, Berlin, I, Part II, p. 19.

Goldschmidt, K.J. (1891). Die Lepra auf Madeira, Leipzig. Quoted by Jeanselme (1934) La Lepre, p. 257.

Goodwin, C.S. (1967). Lepr. Rev. 38, 181.

Holmes, I.B. and Hilson, G.R.F. (1973). Abstracts of Tenth International Leprosy Congress, Bergen, p. 26.

Jeanselme, E. (1934a). La Lepre, p. 324.

Jeanselme, E. (1934b). La Lepre, p. 268.

Jeanselme, E. and Laurens (1897). First International Leprosy Congress, Berlin, I Part II, p. 19.

Kirchheimer, W.F. (1973). Personal Communication.

Klingmuller, V. (1930). Die Lepra, p. 349.

Leloir, H. (1886). Traite Pratique et Theoretique de la Lepre, Paris, p. 71.

McDougall, A.C., Rees, R.J.W. and Weddell, A.G.M. (1973). Abstracts of Tenth International Leprosy Congress, Bergen, p. 29.

McDougall, A.C., Rees, R.J.W., Weddell, A.G.M. and Wajdi Kanan (1974). J. Path. 108, In press.

Muir, E. (1938). Leprosy, Diagnosis and Treatment, 6th ed. Indian Council B.E.L.R.A. p. 100. 
Nolasco, J.O. and Lara, C.B. (1949). Transactions of Fif th International Congress of Leprology, p. 569.

Pedley, J.C. (1970). Lepr. Rev. 41, 31.

Pedley, J.C. (1973a). Lepr. Rev. 44, 33.

Pedley, J.C. (1973b). A bstracts of Tenth International Leprosy Congress, Bergen, p. 29.

Prabhu, M.N. (1946). Leprosy in India XVIII, 10.

Rees, R.J.W. and Davey, T.F. (1973). Paper presented at All India Leprosy Workers' Conference. Leprosy in India. In press.

Rees, R.J.W., McDougall, A.C. and Weddell, A.G.M. (1974). Lepr. Rev. 45 (2), 112.

Rogers, L. and Muir, E. (1946). Leprosy, 3rd ed. p. 152.

Schäffer, X. (1897). First International Leprosy Congress, Berlin, 2, 62.

Schäffer, X. (1898). Arch. Dermat. Syphil. XLIV, 159-174.

Shepard, C.C. (1962). Int. J. Lepr. 30, 10.

Sticker, G. (1897). First International Leprosy Congress, Berlin, 1, Part I, 99-100.

Wade, H.W. (1935). Lepr. Rev. 6, 181. 